\title{
COSY DELL - ROCKY SHORE - INLAND SEA
}

\section{Scientists: Artist:

\author{
Daphne Lee and Zoe Henderson \\ Vivien Dwyer
}

\section{COSY DELL}

\section{Daphne Lee and Zoe Henderson}

Cosy Dell seems an odd name for one of New Zealand's most intriguing fossil sites. Near Waimumu in Southland, it pays tribute to the name of the farm whose owners unearthed a fossil treasure trove in a small lime quarry. Since its discovery in 2009, they have made it possible for hundreds of scientists and students to study an amazing Oligocene rocky shore ecosystem far from the present coastline.

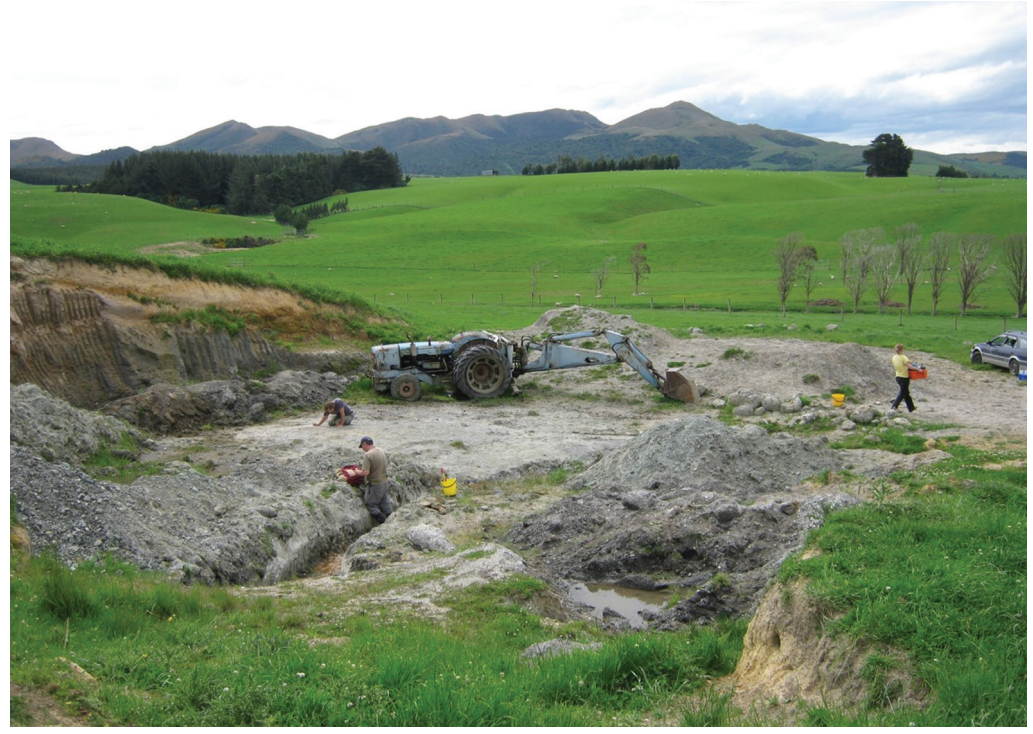

Figure I. Fossil collectors at Cosy Dell,

with the digger that first uncovered the fossil treasure trove in 2009.

At Cosy Dell, some 25 million years ago, subtropical seas lapped up against Jurassic-age basement rocks full of fossil seed ferns. The rocky boulders and the myriads of animals that grew on and around them were preserved by layers of sand and silt and buried beneath swamps that became the Gore Lignite Measures. Cosy Dell has yielded thousands of invertebrate fossils, many preserved in very hard, calcite-cemented concretions.

Molluscs, many with aragonitic shells and colour patterns preserved, are extremely diverse. They include chitons, 90 bivalves and 250 gastropods. Bivalves include oysters encrusting rocks and thick-shelled scallops. 

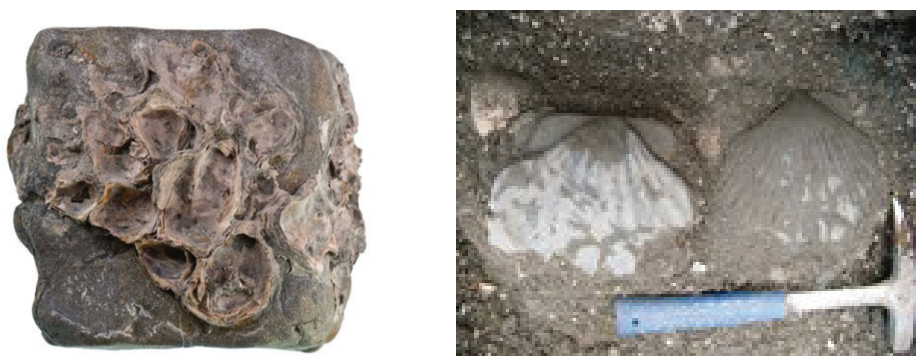

Figure 2. Boulder with oysters in life position and huge scallop shells, with a geology hammer for scale.
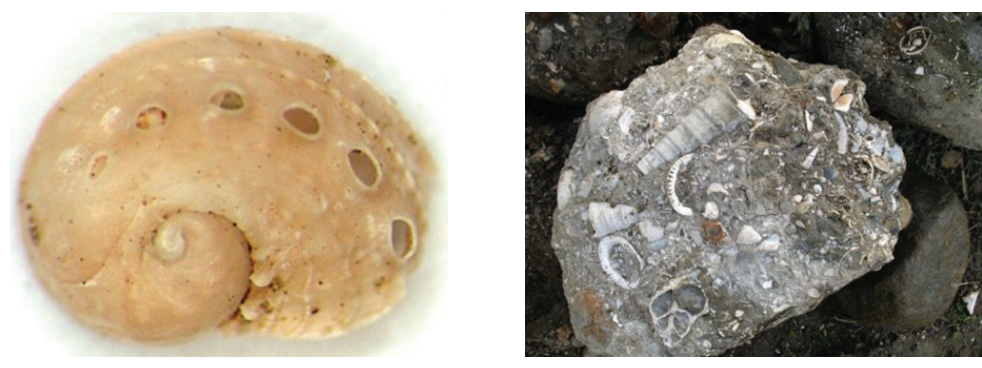

Figure 3. Tiny pāua, about $3 \mathrm{~mm}$ across, and giant turret shell in a concretion.

Gastropods include pāua and giant turret shells.

In addition, there are intertidal and subtidal barnacles, 120 species of microscopic ostracods, brachiopods, echinoids and waterworn reef-corals.

The rich vertebrate fauna of thousands of otoliths (earbones) at Cosy Dell shows that the shallow, warm Chatton seas swarmed with fish, including sharks and rays. Large, middle-sized and small penguins nested on the shores. Drift seeds of a tropical legume, seagrass limpets, mangrove snails, petrified logs and the pollen flora testify to a diverse subtropical coastal rainforest with nearby mangroves and seagrass meadows.

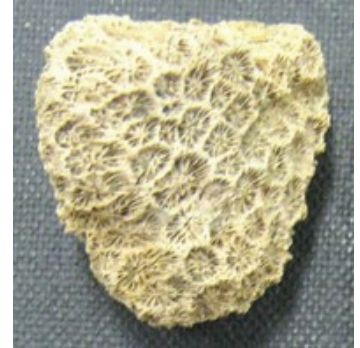

Figure 4. Reef-coral from the ancient subtropical sea.

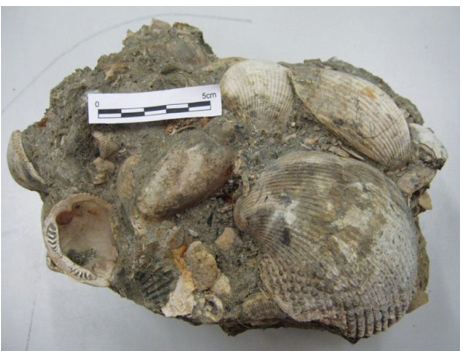

Figure 5. Cosy Dell concretions with petrified wood and shells. 


\section{COSY DELL}

\section{Vivien Dwyer}

My first experience of Cosy Dell was as part of a Rock and Mineral Club trip looking for shells, corals and other things of interest at the site of the University of Otago's dig. We knew that anything of interest to them would become part of their collection. There was a lot of fascinating stuff including all of the above, along with some exploration of an old coal mine which is also in the area. I took this as my starting point, taking sketches and photos, and then tried to imagine what the place had looked like when all these fossils were alive.

I chose the weaving loom as my workplace and, using a variety of threads, set out to create the feel of the place - not forgetting a small representation of the coal deposit. I also added some of the tusk shells from the site (although most of what I collected was either too small or overly fragile). I fashioned the weaving as a number of layers showing the stratification that occurs as time goes by.

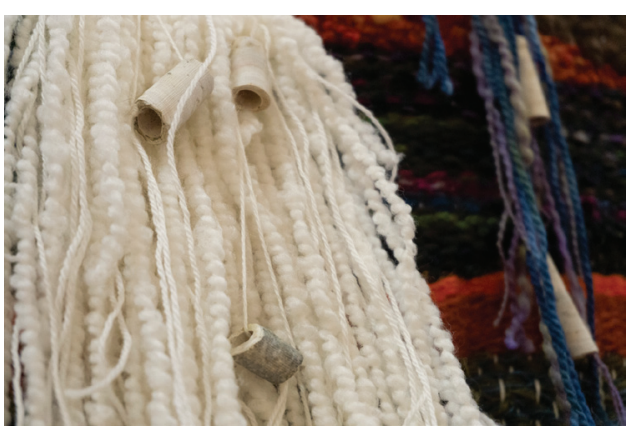

Figure 6. (detail).

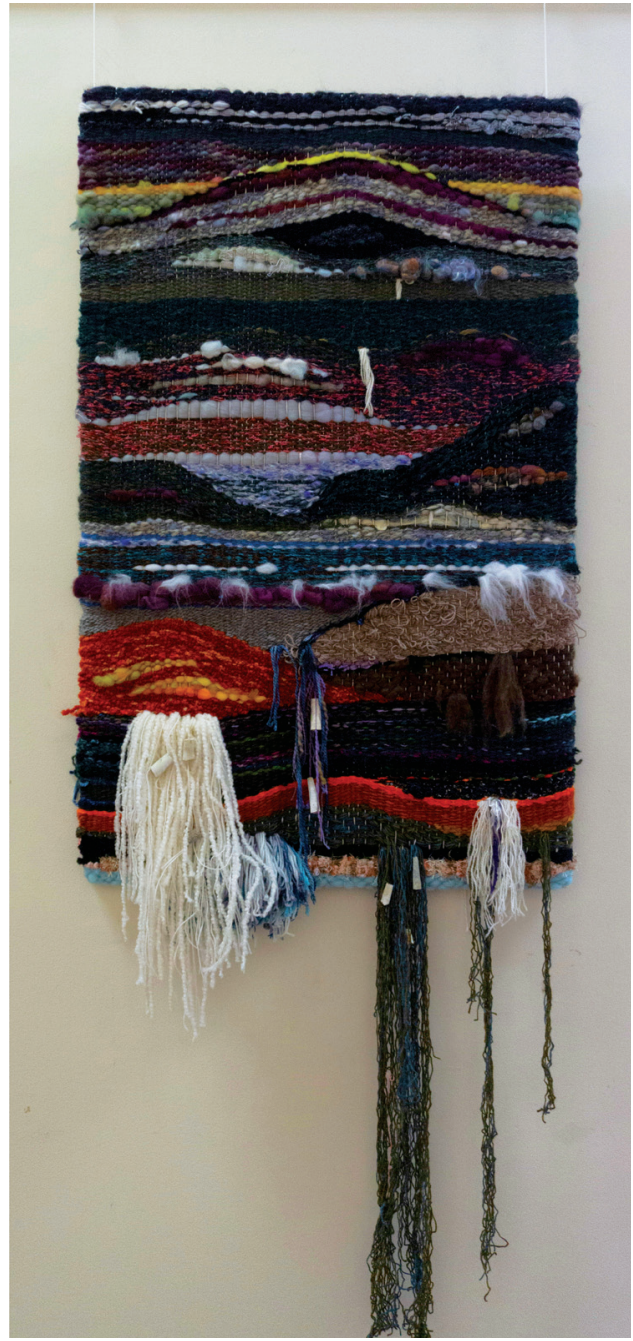

Figure 7.Vivien Dwyer, Cosy Dell, woven tapestry, embellished with small fossils from site dig, $600 \mathrm{~mm} \times 970 \mathrm{~mm}$.

Daphne Lee is an Honorary Associate Professor in the Department of Geology at the University of Otago, Dunedin. Her research interests encompass Cenozoic paleobotany and paleoclimate, Cenozoic invertebrate paleontology, Brachiopoda and Cenozoic stratigraphy.

Zoe Henderson is a Research Assistant in the Department of Geology at the University of Otago, Dunedin.

Vivien Dwyer is a graduate from the Otago Polytechnic where she completed her MVA. She has been an artist for most of her life and returned to Art School after her children grew up and became independent. She works in textile art with a special focus on printmaking and tapestry weaving. 